\title{
STATUS SUMBERDAYA IKAN EKOR KUNING (Caesio cuning) PADA MUSIM PERALIHAN DI PERAIRAN KARIMUNJAWA: SUATU PENDEKATAN MENGGUNAKAN SPAWNING POTENTLAL RATIO
}

\section{Resource Status of Yellow-Tail Fish in Transitional Season in Karimunjawa Waters: An Approach Using the Spawning Potential Ratio}

Oleh:

\author{
Regi Darmawan ${ }^{1}$, Budy Wiryawan ${ }^{1 *}$, Prihatin Ika Wahyuningrum ${ }^{1}$ \\ ${ }^{1}$ Departemen Pemanfaatan Sumberdaya Perikanan, Fakultas \\ Perikanan dan Ilmu Kelautan, Institut Pertanian Bogor \\ *Korespondensi penulis: budywi@apps.ipb.ac.id
}

\begin{abstract}
ABSTRAK
Ikan ekor kuning (Caesio cuning) merupakan hasil tangkapan yang dominan ditangkap oleh nelayan Karimunjawa. Tingkat pemanfaatan ikan ekor kuning cukup tinggi sehingga perlu adanya pengaturan dalam pengelolaan agar sumberdaya ikan ekor kuning tetap terjaga. Penelitian ini bertujuan untuk mengevaluasi status sumberdaya ikan ekor kuning pada musim peralihan bulan Maret-April 2018. Metode yang digunakan adalah teknik Length-Based Spawning Potential Ratio (LB-SPR). Hasil penelitian memperlihatkan bahwa kondisi stok sumberdaya ikan ekor kuning pada bulan Maret-April 2018 (musim peralihan I) under exploited dengan nilai kematian diakibatkan penangkapan (F/M) sebesar 1,44, Spawning Potential Ratio (SPR) 0,50 dan rata-rata ukuran ikan yang tertangkap lebih besar dari nilai panjang pertama kali matang gonad (SL50>Lm) sehingga penambahan upaya sebesar $10 \%$ pada musim peralihan masih memungkinkan. Pada penelitian sebelumnya pada bulan JanuariFebruari 2017 (musim barat) kondisinya telah tereksploitasi secara berlebih dengan nilai kematian diakibatkan penangkapan (F/M) 2,75, Spawning Potential Ratio (SPR) 0,18 dan rata-rata ukuran ikan yang tertangkap lebih kecil dari nilai panjang pertama kali matang gonad SL50<Lm. Oleh karena itu, pengaturan terkait jumlah penangkapan perlu diatur sesuai musim penangkapan agar terciptanya perikanan ekor kuning yang berkelanjutan.
\end{abstract}

Kata kunci: alat tangkap, Karimunjawa dan spawning potential ratio

\begin{abstract}
Yellow-tail (Caesio cuning) is dominant fish caught by fisherman from Karimunjawa. It has been indicated as an overexploited stock; therefore, rules are required to manage the stocks for achieving sustainable fisheries. The purpose of the study was to describe fishing gear used by fisherman and evaluation status of yellow tail fish resources in a transition season (March-April 2018). The method used Length-Based Spawning Potential Ratio (LB-SPR) technique. Results showed that the status of yellow-tail fish on March-April 2018 (transition season) was underexploited with values of fishing mortality to natural maturity (F/M) is 1,44, Spawning Potential Ratio (SPR) is 0,50 and rate length proportional caught more significant than a length at first maturity (SL50>Lm) so an additional effort $10 \%$ is still possible. In the previous study on January-February 2017 (west season), the status of yellowtail fish was overexploited with values of fishing mortality to natural mortality (F/M) is 2,75, Spawning Potential Ratio was 0,18 and rate length proportional caught smaller than a length at first maturity $(S L 50<L \mathrm{~m})$. Therefore, sum of fishing trip must be regulated according to fishing season so that it can create sustainable fisheries.
\end{abstract}

Key words: fishing gear, Karimunjawa and spawning potential ratio 


\section{PENDAHULUAN}

Kepulauan Karimunjawa terdiri atas kelompok pulau-pulau kecil yang berjumlah 27 pulau. Karimunjawa ditetapkan sebagai taman nasional dengan nama Taman Nasional Karimunjawa (TNKJ). Kegiatan perikanan di TNKJ terpusat di Pulau Karimunjawa, yaitu di PPP Karimunjawa. Kegiatan perikanan tangkap di Karimunjawa dikategorikan menjadi dua, yaitu perikanan karang dan perikanan pelagis (Irnawati et al. 2011). Ikan ekor kuning salah satu komoditas ikan karang dan biasanya di konsumsi oleh masyarakat di Kepulauan Karimunjawa. Ikan karang memiliki habitat atau ekosistem di terumbu karang. Terumbu karang dijadikan sebagai tempat pemijahan (spawning ground), pengasuhan (nursery ground) dan mencari makan (feeding ground) (Utomo et al. 2013).

Stok sumberdaya ikan karang di Taman Nasional Karimunjawa mengalami pemanfaatan secara berlebih atau over exploited dan penangkapan ikan ekor kuning dilakukan selama sepanjang tahun (Yuliana et al. 2016). Kondisi ini sesuai dengan penelitian sebelumnya yang dilakukan pada musim barat yang menunjukkan tingkat eksploitasi berlebih dengan nilai Spawning Potential Ratio kurang dari 20\% dan nilai produksi hasil tangkapan ikan ekor kuning mengalami penurunan dari $94,42 \mathrm{~kg}$ pada tahun 2012 menjadi 57,05 kg pada tahun 2016 (Pratiwi 2017). Nelayan yang menggunakan alat tangkap panah (speargun) dan bubu untuk menangkap ikan ekor kuning (Caesio cuning) akan terjadi secara terus menerus selama sepanjang tahun sehingga dapat mengancam keberlanjutan sumberdaya ikan ekor kuning (Caesio cuning).

Penangkapan ikan perlu memperhatikan kondisi biologis dari sumberdaya ikan tersebut agar ikan yang tertangkap sudah layak tangkap. Saat ini pendugaan stok berdasarkan biologis ikan dapat dilakukan dengan mengkaji nilai rasio potensi pemijahannya atau Spawning Potential Ratio(SPR). SPR adalah rasio antara jumlah ikan yang memijah selama hidupnya dengan adanya penangkapan dibagi dengan jumlah ikan yang memijah tanpa adanya penangkapan (Brook et al. 2010).

Status stok dari ikan ekor kuning yang berada di suatu perairan dapat dicari melalui pengkajian dengan menggunakan metode Length-Based Spawning Potential Ratio (LB-SPR). Length-Based Spawning Potential Ratio (LB-SPR) merupakan suatu indeks laju relatif reproduksi pada stok sumberdaya ikan yang sudah tereksploitasi. Teknik LB-SPR merupakan cara alternatif untuk mengestimasi nilai kematian akibat penangkapan terhadap kematian alami (F/M), selektivitas dan Spawning Potential Ratio berdasarkan data panjang ikan yang tertangkap. Data panjang ikan paling disukai dan mudah didapatkan dalam pengumpulan data, selain itu pada perikanan yang minim data biasanya yang tersedia hanya panjang ikan saja (Hordyk et al. 2014).

Penelitian ini sangat penting karena dengan mengkaji rasio potensi pemijahan ikan ekor kuning pada musim peralihan dapat memberikan evaluasi terkait status stok dari sumberdaya ikan yang ada di perairan Karimunjawa untuk pengelolaan perikanan. Hasil penelitian ini diharapkan dapat menjadi bahan pertimbangan dalam perencanaan pengelolaan bagi pihak pengelola perikanan di perairan Karimunjawa terkait kondisi status stok sumberdaya ikan ekor kuning ketika pada musim peralihan. Tujuan penelitian ini yaitu mengevaluasi status sumberdaya ikan ekor kuning dengan metode Spawning Potential Ratio pada musim peralihan (Maret-April 2018).

\section{METODE PENELITIAN}

Penelitian ini dilaksanakan di Kepulauan Karimunjawa. Pelaksanaan observasi lapang dilaksanakan pada tanggal 20 Maret 2018 sampai 20 April 2018.

Objek yang digunakan dalam penelitian ini yaitu ikan ekor kuning (Caesio cuning). Alat yang digunakan yaitu telepon genggam dan kamera untuk penyimpanan dokumentasi, alat tulis untuk mencatat data yang diperlukan dalam penelitian, kuesioner digunakan untuk mendapatkan informasi dari narasumber/nelayan terkait data yang dibutuhkan dalam penelitian, Ms. Excel dan R Studio digunakan untuk melakukan pengolahan data yang telah diperoleh selama penelitian. 
Data yang dibutuhkan yaitu panjang cagak (fork length), tingkat kematangan gonad, data panjang ikan ekor kuning saat pertama kali matang gonad $(L m)$, koefisien pertumbuhan dari ikan ekor kuning $(K)$, laju kematian alami $(M)$, dan panjang asimptotik $(L \infty)$ dan alat tangkap yang digunakan untuk menangkap ikan ekor kuning. Data diperoleh dari hasil wawancara kepada nelayan, membedah ikan ekor kuning dari tingkat kematangan gonadnya dan mengukur panjang cagak ikan ekor kuning.

Teknik sampling yang digunakan yaitu accidental sampling. Kapal nelayan yang digunakan menangkap ikan ekor kuning yaitu kapal bubu dan kapal panah. Data sebaran ikan ekor kuning diambil dari 6 unit kapal yaitu 2 unit kapal bubu dan 4 unit kapal panah. Satu unit kapal terdapat 3-5 nelayan. Pengambilan sampel dilakukan pada saat kapal melakukan pendaratan ikan. Sampel diambil secara acak sebanyak 30 ekor yang terdapat pada box ketika didaratkan kemudian sampel tersebut diukur panjang cagaknya. Hasil yang didapatkan selama penelitian jumlah sampel ikan ekor kuning (Caesio cuning) sebanyak 400 ekor dan sampel tingkat kematangan gonad sebanyak 30 ekor. Jenis dan metode pengumpulan data disajikan pada Tabel 1.

Tabel 1 Jenis dan metode pengumpulan data

\begin{tabular}{llll}
\hline \multicolumn{1}{c}{ Tujuan } & \multicolumn{1}{c}{$\begin{array}{c}\text { Jenis data yang } \\
\text { dibutuhkan }\end{array}$} & $\begin{array}{c}\text { Cara pengumpulan } \\
\text { data }\end{array}$ & $\begin{array}{c}\text { Cara menganalisis } \\
\text { data }\end{array}$ \\
\hline $\begin{array}{l}\text { Mengevaluasi status } \\
\text { sumberdaya ikan ekor } \\
\text { kuning pada musim } \\
\text { peralihan }\end{array}$ & $\begin{array}{l}\text { Ukuran panjang cagak } \\
\text { ikan ekor kuning }\end{array}$ & $\begin{array}{l}\text { Pengukuran langsung } \\
\text { di lapangan } \\
\text { Pembedahan ikan } \\
\text { ekor kuning }\end{array}$ & $\begin{array}{l}\text { Spawning } \\
\text { Potential Ratio }\end{array}$ \\
& $\begin{array}{l}\text { Tingkat kematangan } \\
\text { gonad ikan ekor kuning }\end{array}$ & & klasikasi tingkat \\
& & & kematangan gonad \\
\hline
\end{tabular}

Pengambilan sampel dilakukan dengan cara simple random sampling. Simple random sampling merupakan teknik pengambilan sampel dari populasi yang dilakukan secara acak tanpa memperhatikan strata yang ada di dalam populasi tersebut, sehingga anggota populasi yang sama memiliki peluang yang sama untuk terpilih (Sugiyono 2016). Penelitian yang akan menggunakan analisis data dengan statistik, jumlah sampel paling sedikit adalah 30 (Baiky 1982 dalam Sukandarrumidi 2012).

Status stok dari ikan ekor kuning dikaji dengan cara menggunakan metode Spawning Potential Ratio(SPR) yang merupakan suatu indeks laju relatif reproduksi pada stok sumberdaya ikan yang sudah tereksploitasi. SPR adalah rasio antara jumlah ikan yang memijah selama hidupnya yang telah tertangkap dibagi dengan jumlah ikan yang memijah tanpa adanya penangkapan (Brook et al. 2010). Metode LB-SPR membutuhkan komposisi data panjang dari hasil tangkapan, seperti nilai M/K, panjang asimptotik $(L \infty)$ dan $C V L \infty$. Parameter-parameter estimasi yang digunakan untuk menghitung nilai SPR adalah nilai selektivitas terhadap panjang dan rasio penangkapan terhadap kematian alami. Semua pemodelan simulasi dapat dilakukan pada software R Studio (Hordyk et. al 2014).

Asumsi yang digunakan dalam pemodelan Length-Based Spawning Potential Ratio (LB-SPR) yaitu frekuensi panjang ikan yang tertangkap dianggap mewakili stok, data panjang ikan betina, kurva selektivitas berpola asimtotik, tersedia data matang gonad pada ukuran tertentu dan stok berada pada titik keseimbangan. Penghitungan SPR dilakukan dengan software R Studio. Parameter-parameter yang dimasukkan adalah nilai $M / K, L \infty, C V L \infty, L 50$ dan $L 95$. Parameter yang akan diestimasi adalah nilai $F / M$, SL50, SL95 dan SPR (Hordyk et al. 2014).

Nilai acuan berdasarkan (Prince et al. 2014), di mana status perikanan dapat diklasifikasikan menjadi 3 golongan, seperti Tabel 2 di bawah ini. 
Tabel 2 Persentase kondisi perairan berdasarkan SPR

\begin{tabular}{ll}
\hline \multicolumn{1}{c}{ Kondisi } & \multicolumn{1}{c}{ Persentase (\%) } \\
\hline Under exploited (belum tereksploitasi) & $S P R>40 \%$ \\
Moderate (sedang) & $20 \%<S P R<40 \%$ \\
Over exploited (tangkap lebih) & $S P R<20 \%$ \\
\hline
\end{tabular}

Sumber: Prince et al. 2014

Analisis SPR menggunakan software R Studio dengan memasukkan parameter-parameter yang dibutuhkan. Lm atau Length at first maturity merupakan salah satu data yang dibutuhkan untuk melakukan monitoring stok ikan pada jenis ikan tertentu di suatu wilayah apakah ikan tersebut sudah tereksploitasi ketika masih kondisi juvenil. Nilai $L m$ didapatkan melalui data panjang maksimum selama observasi ( $L \max$ ) dan $L \infty$. Parameter lain yang digunakan untuk mengestimasi SPR yaitu tingkat kematian alami $(M)$ (Froese dan Binohlan 2000).

1) Mengestimasi nilai $L \infty$ dari nilai $L \max$

$\log (L \infty)=0.044+0.9841 * \log (\operatorname{Lmax})$

$L \infty=10^{\wedge} \log (L \infty)$

2) Mengestimasi nilai $L m$ dari nilai $L \infty$

$\log (L m)=0.8979 * \log (L \infty)-0.0782)$

$\mathrm{Lm}=10^{\wedge} \log (\mathrm{Lm})$

3) Mengestimasi nilai kematian alami $(M)$ dari nilai $L \infty$ dan $K$

$\log (M)=-0.0066-0.279 \log (L \infty)+0.6543 \log (K)+0.4634 \log (T)$

$M=10^{\wedge} \log (M)$

Tingkat kematangan gonad ditentukan melalui pengamatan pada gonad dari sampel ikan yang diamati. Pengamatan gonad dilakukan dengan dua cara, yaitu secara morfologis dan histologis. Pengamatan secara morfologis dilakukan langsung di lapang dengan melihat bentuk, ukuran, warna dan perkembangan gonad. Pengamatan histologis dilakukan di laboratorium untuk mengetahui anatomi perkembangan gonad lebih jelas dan mendetail dengan menggunakan mikroskop (Effendie 1997). Menurut Romimohtarto dan Juwana (2001) klasifikasi tingkat kematangan gonad tercantum pada Tabel 3.

Tabel 3 Klasifikasi tingkat kematangan gonad

\begin{tabular}{|c|c|c|}
\hline TINGKAT & KEADAAN GONAD & DESKRIPSI \\
\hline $\mathrm{I}$ & Tidak matang (immature) & $\begin{array}{l}\text { Gonad memanjang, kecil hampir } \\
\text { transparan. }\end{array}$ \\
\hline II & Sedang matang (maturing) & $\begin{array}{l}\text { Gonad membesar, berwarna jingga } \\
\text { kekuning-kuningan, butiran telur belum } \\
\text { dapat terlihat. }\end{array}$ \\
\hline III & Matang (mature) & $\begin{array}{l}\text { Gonad berwarna putih kekuning- } \\
\text { kuningan, butiran telur sudah dapat terlihat } \\
\text { dengan mata telanjang. }\end{array}$ \\
\hline IV & Siap pijah (ripe) & $\begin{array}{l}\text { Butiran telur membesar dan berwarna } \\
\text { kuning jernih, dapat keluar dengan sedikit } \\
\text { penekanan pada bagian perut. }\end{array}$ \\
\hline $\mathrm{V}$ & Pijah (spent) & $\begin{array}{l}\text { Gonad mengecil, berwarna merah dan } \\
\text { banyak terdapat pembuluh darah. }\end{array}$ \\
\hline
\end{tabular}

Sumber: Romimohtarto dan Juwana 2001 


\section{HASIL DAN PEMBAHASAN}

\section{Evaluasi Status Sumberdaya Ikan Ekor Kuning}

Salah satu hasil tangkapan utama di perairan Karimunjawa adalah ikan ekor kuning. Ikan tersebut ditangkap dengan alat tangkap panah dan bubu. Produksi ikan ekor kuning di perairan Karimunjawa mengalami penurunan, karena adanya indikasi penangkapan ikan yang berlebih pada musim tertentu sehingga sumberdaya ikan semakin berkurang. Kondisi perikanan karang di wilayah Taman Nasional Karimunjawa sudah mengalami penangkapan secara berlebih atau over exploited (Yuliana et al. 2016).

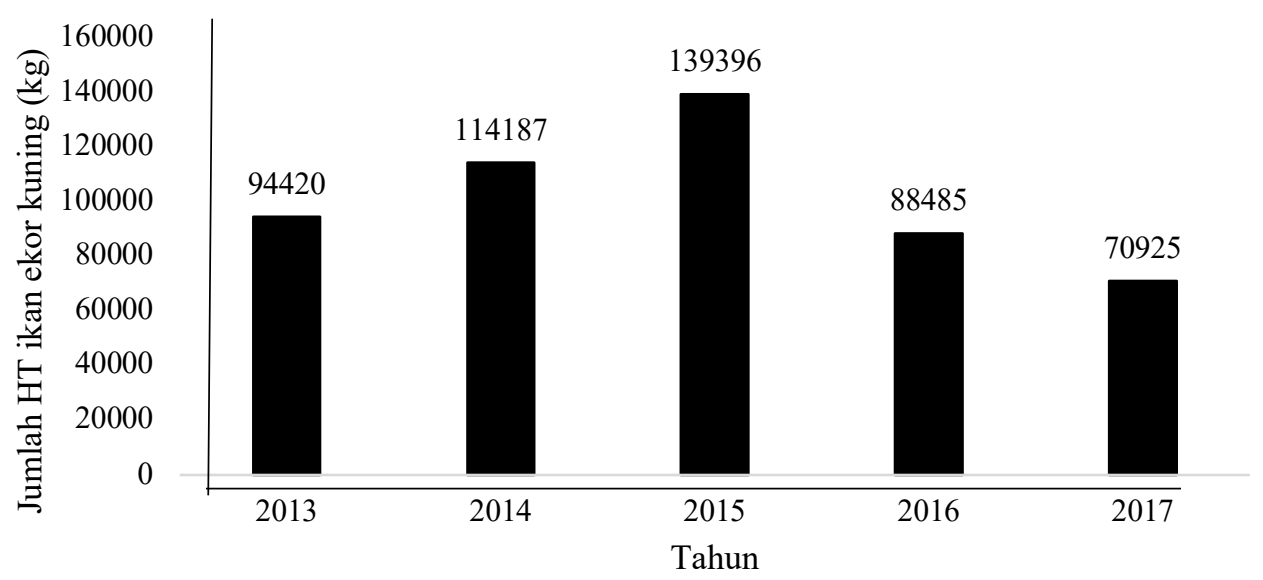

Gambar 1 Produksi hasil tangkapan ikan ekor kuning (kg) di PPP Karimunjawa (sumber: PPP Karimunjawa 2018)

Gambar 1 menunjukkan bahwa produksi ikan ekor kuning berfluktuasi namun pada tiga tahun terakhir (tahun 2015-2017) produksi ikan ekor kuning mengalami penurunan karena jumlah upaya penangkapan mengalami penurunan pada tahun 2015 dan 2016 yaitu 1693 trip dan 583 trip (PPP Karimunjawa 2018). Namun penulis masih belum bisa menunjukkan apakah menurunnya produksi disebabkan oleh berkurangnya jumlah trip, karena data trip yang tersedia hanya pada tahun 2015 dan 2016 saja. Faktor yang menjadi pengaruh penurunan upaya penangkapan dari nelayan yaitu kondisi cuaca yang tidak baik, adanya mata pencaharian lain yaitu di bidang pariwisata seperti pemandu wisata di Pulau Karimunjawa dan perubahan alat tangkap yang digunakan.

\section{Spawning Potential Ratio(SPR)}

Gambar 2 merupakan histogram dari sebaran panjang cagak ikan ekor kuning yang didapatkan selama penelitian. 


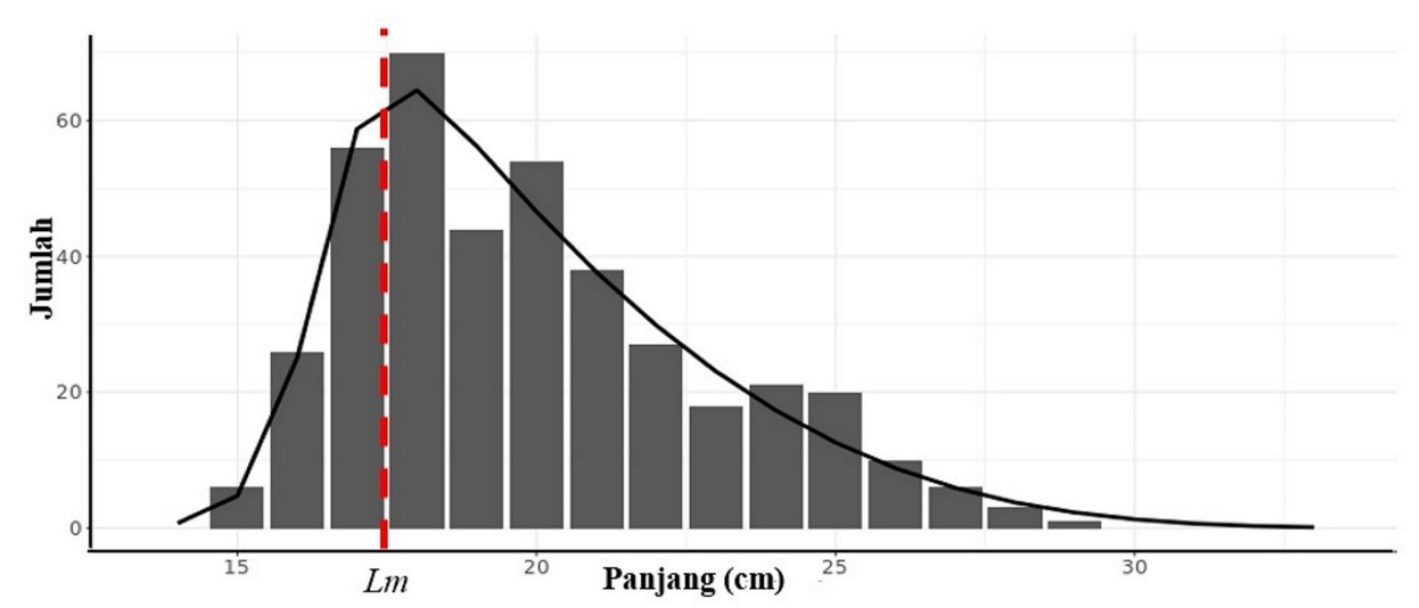

Gambar 2 Sebaran panjang cagak ikan ekor kuning

Sebaran ikan ekor kuning yang tertangkap menunjukkan sebaran normal. Jumlah ikan ekor kuning yang didapat selama penelitian yaitu sebanyak 400 ekor ikan. Ikan dikatakan layak tangkap apabila panjangnya lebih besar dari nilai Lm, dari 400 ekor ikan ekor kuning ada 119 ekor (30\%) yang panjang nya kurang dari nilai Lm maka ikan tersebut tidak layak tangkap. Sedangkan ikan layak tangkap yang panjangnya lebih dari nilai $L m$ yaitu sebanyak 281 ekor (70\%). Length at First Maturity $(L m)$ adalah panjang pertama kali ikan matang gonad. Hasil perhitungan nilai panjang pertama kali ikan ekor kuning matang gonad $(L m)$ dengan menggunakan metode Froese dan Binohlan pada penelitian yaitu sebesar 17,9 cm (ukuran panjang cagak). Beberapa penelitian lainnya terkait nilai $L m$ ikan ekor kuning seperti pada Tabel 4.

Tabel 4 Nilai Lm ikan ekor kuning

\begin{tabular}{lccc}
\hline \multicolumn{1}{c}{ Lokasi Perairan } & $\begin{array}{c}\text { Length at First Maturity } \\
(\mathrm{cm})\end{array}$ & $\begin{array}{c}\text { Waktu } \\
\text { Penelitian }\end{array}$ & Sumber \\
\hline $\begin{array}{l}\text { Perairan Karimunjawa } \\
\text { Perairan Kepulauan }\end{array}$ & 20,25 & 2011 & Triyono et al. (2011) \\
Seribu & $21,8-21,9$ & Mei-Jun 2011 & Habibun (2011) \\
Perairan Karimunjawa & & & \\
\multicolumn{1}{c}{-} & 20,1 & Jan-Feb 2017 & Pratiwi (2017) \\
& 17,9 (panjang cagak) & - & fishbase.org (2018) \\
\hline
\end{tabular}

Salah satu aspek biologi yang digunakan untuk mengetahui kondisi ikan tersebut melalui organ reproduksi ikan yaitu perkembangan gonadnya. Pengamatan gonad dilakukan dengan dua cara, yaitu secara morfologis dan histologis. Pengamatan secara morfologis dilakukan langsung di lapang dengan melihat bentuk, ukuran, warna dan perkembangan gonad. Pengamatan histologis dilakukan di laboratorium untuk mengetahui anatomi perkembangan gonad lebih jelas dan mendetail dengan menggunakan mikroskop (Effendie 1997). Sampel ikan ekor kuning yang digunakan untuk menguji tingkat kematangan gonad sebanyak 30 ekor, dari 30 ekor ikan ekor kuning (Caesio cuning) sebanyak 1 ekor (3\%) TKG I (ukuran panjang cagak 15-16,5cm), 11 ekor (37\%) TKG II (ukuran panjang cagak 17-18,4cm), 11 ekor (37\%) TKG III (ukuran panjang cagak 18,5-20,5cm) dan 7 ekor (23\%) TKG IV (ukuran panjang cagak 20,6-22cm). Ikan dikatakan telah matang gonad umumnya ketika mencapai TKG III (Effendie 1997). Gambar tingkat kematangan gonad dan persentase TKG terdapat pada Gambar 3 dan 4. 


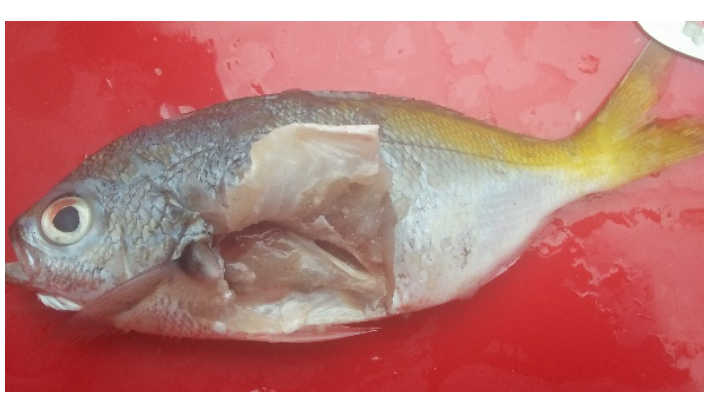

TKG I

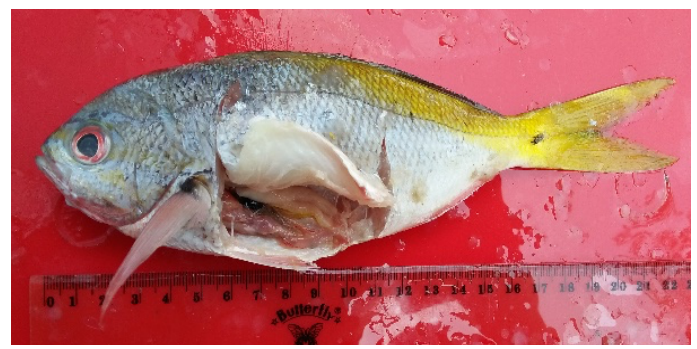

TKG III

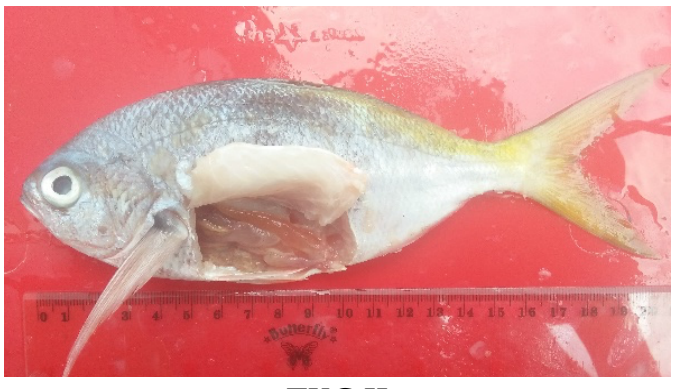

TKG II

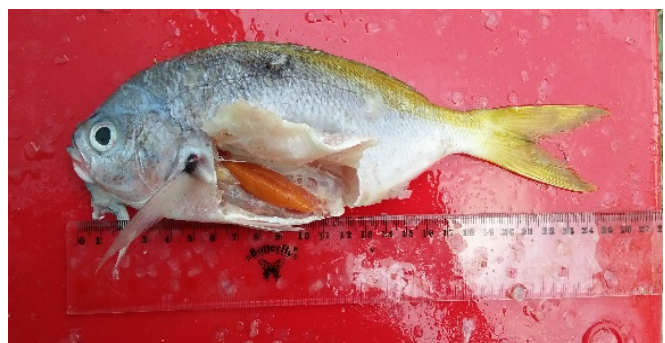

TKG IV

Gambar 3 Tingkat kematangan gonad ikan ekor kuning

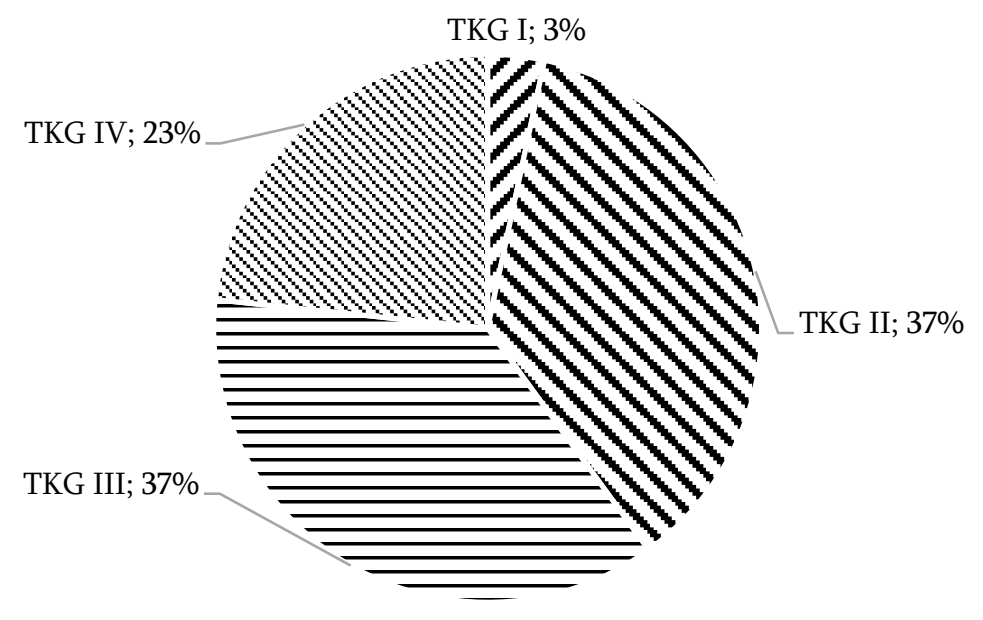

Gambar 4 Persentase tingkat kematangan gonad ikan ekor kuning

Tabel 5 Estimasi perhitungan SPR ikan ekor kuning pada musim peralihan

\begin{tabular}{|c|c|}
\hline Parameter & Karimunjawa (Maret-April 2018) \\
\hline Lm (Length at First Maturity) & $18,2 \mathrm{~cm}$ \\
\hline Lo (Length Asympthotic) & $30,4 \mathrm{~cm}$ \\
\hline Lmax (Length Maximum) & $29 \mathrm{~cm}$ \\
\hline$K$ & 0,42 \\
\hline$M{\text { (Mortality })^{*}}^{*}$ & 0,99 \\
\hline$T($ Temperature $)$ & $28^{\circ} \mathrm{C}$ \\
\hline SPR (Spawning Potential Ratio) & 0,50 \\
\hline$F / M^{*}$ & 1,44 \\
\hline$S L 50^{*}$ & $23,52 \mathrm{~cm}$ \\
\hline$S L 95^{*}$ & $33,81 \mathrm{~cm}$ \\
\hline
\end{tabular}


Nilai kematian (Tabel 5) yang diakibatkan penangkapan terhadap kematian alaminya (F/M) menunjukkan nilai 1,44 yang artinya nilai kematian yang diakibatkan oleh penangkapan atau fishing lebih besar dari nilai kematian. Namun, penangkapan ikan ekor kuning yang dilakukan di perairan Karimunjawa pada bulan Maret-April 2018 masih belum berlebihan karena nilai SPR nya berada di atas $40 \%$.

Penelitian sebelumnya (Pratiwi 2017) nilai F/M sebesar 2,75. Hal ini menunjukkan bahwa tingkat tekanan terhadap penangkapan di musim barat cukup tinggi dan dapat menyebabkan eksploitasi secara berlebihan.

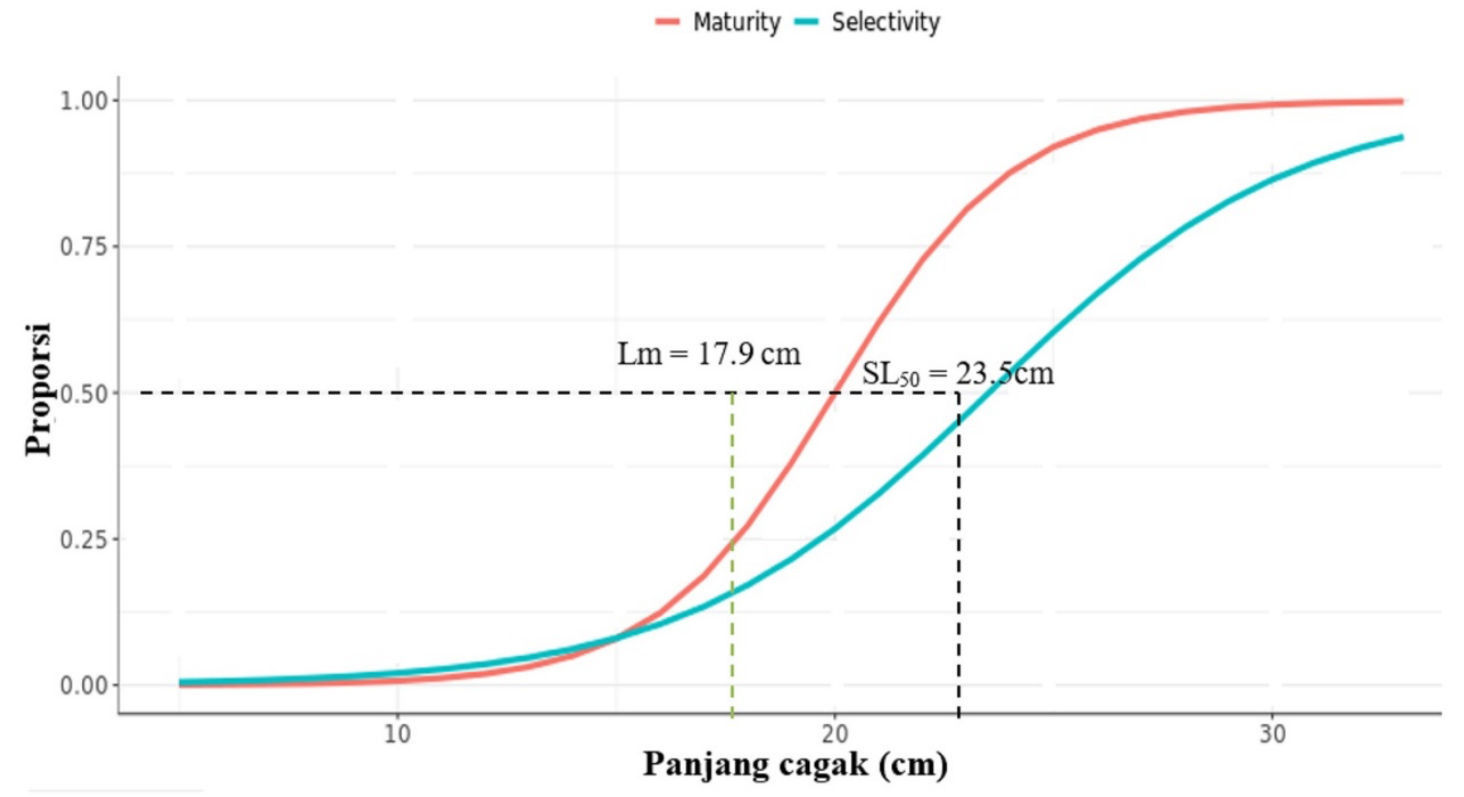

Gambar 5 Kurva maturity-selectivityikan ekor kuning pada bulan Maret-April 2018

Proporsi ukuran rata-rata ikan ekor kuning yang tertangkap $\left(S L_{50}\right)$ adalah $23,5 \mathrm{~cm}$ dan ukuran ikan ekor kuning yang matang gonad yaitu sebesar $17,9 \mathrm{~cm}$. Hal ini menunjukkan bahwa nilai $S L_{50}$ lebih besar dari nilai $L m$ sehingga ikan yang tertangkap sebagian besar sudah layak tangkap. Garis selektivitas berada di atas dari garis matang gonad menunjukkan bahwa selektivitas alat tangkap sudah baik karena sudah menangkap ikan yang berukuran layak tangkap.

Proporsi ukuran Ikan ekor kuning yang tertangkap pada musim barat di perairan Karimunjawa terdapat pada Gambar 6. 


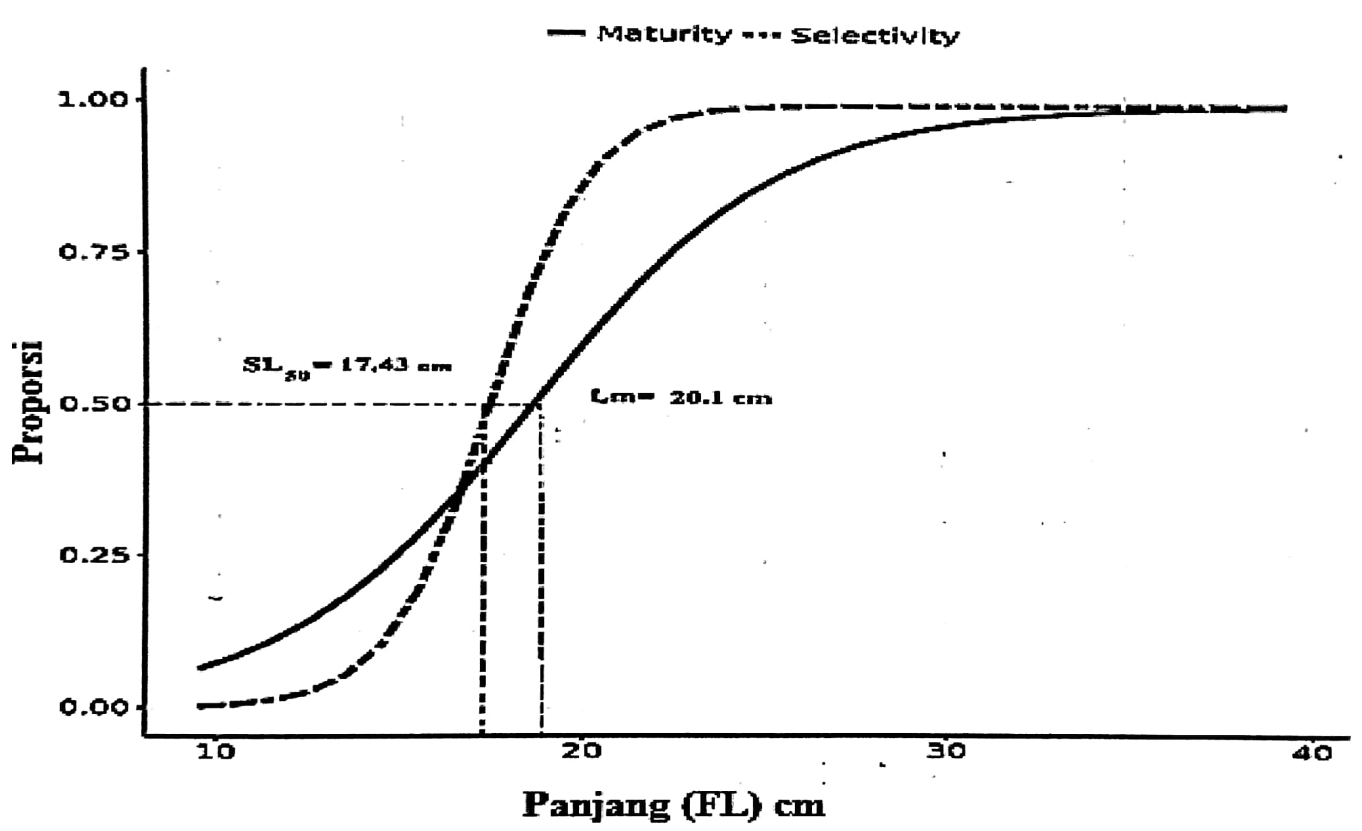

Gambar 6 Kurva maturity-selectivity ikan ekor kuning pada bulan Januari-Februari 2017 (sumber: Pratiwi 2017)

Nilai $L m$ pada penelitian sebelumnya (Pratiwi 2017) yaitu sebesar 20,1 cm. Nilai $L m$ di atas selektivitas mengindikasikan bahwa ikan yang tertangkap masih banyak yang tidak layak tangkap sehingga apabila terus terjadi penangkapan dapat menyebabkan sumberdaya ikan tereksploitasi secara berlebihan.

Volume produksi ikan ekor kuning di perairan Karimunjawa pada tahun 2016 mengalami penurunan. Upaya pemanfaatan aktual perikanan karang masih lebih rendah dari MEY dan MSY. Hal ini merupakan peluang besar untuk meningkatkan produksi ikan ekor kuning dengan adanya penambahan upaya penangkapan di perairan Karimunjawa (Simbolon et al. 2016). Volume produksi ikan ekor kuning pada tahun 2017 mengalami penurunan kembali dikarenakan upaya penangkapan yang menurun dan nelayan memiliki pekerjaan lain yaitu menjadi petambak ikan dan menjadi pemandu wisata atau menyewakan kapalnya untuk digunakan oleh wisatawan.

Ikan ekor kuning yang ditangkap oleh nelayan Karimunjawa memiliki ukuran yang beragam. Hasil tangkapan yang ditangkap perlu diperhatikan, karena ukuran ikan dapat berpengaruh terhadap kondisi biologis dari ikan tersebut. Faktor internal dari pertumbuhan biologisnya yaitu keturunan, umur, jenis kelamin, parasit dan penyakit. Faktor internal umumnya sulit untuk dikontrol. Faktor eksternalnya yaitu kandungan oksigen terlarut, suhu, amonia, fotoperiod (panjang hari) dan ukuran ikan kematangan gonadnya. Ikan yang layak tangkap adalah ketika kematangan gonadnya sudah memasuki tahap III (pijah) (Effendie 1997). Ikan yang ditangkap harus dalam keadaan layak tangkap atau ikan yang sudah memijah, apabila ikan yang tertangkap tidak layak maka dapat menyebabkan tidak adanya kesempatan ikan untuk melakukan rekrutmen atau bereproduksi untuk menghasilkan keturunan.

Pendugaan status stok sumberdaya ikan dapat diketahui melalui pendekatan pemodelan LengthBased Spawning Potential Ratio (LB-SPR). Simulasi pemodelan LB-SPR ini sangat efektif ketika dihadapkan dengan permasalahan minimnya data perikanan di suatu daerah. Selain itu, dengan adanya teknik ini dapat menjadi alat untuk melakukan monitoring di suatu daerah dan menganalisa tindakan yang harus dilakukan untuk kedepannya agar sumberdaya ikan di daerah tersebut tetap terjaga (Hordyk et al. 2014). Nilai SPR yang dihasilkan pada bulan Maret-April 2018 (musim peralihan I) yaitu sebesar $50 \%$ atau 0,50 yang artinya termasuk kategori under exploited dan hasil tangkapannya banyak yang 
berukuran layak tangkap karena berada di atas nilai $L m$. Selama nilai SPR berada di atas nilai 40\% (titik pemanfaatan lestari/sustainability reference points), maka kondisi stok sumberdaya ikan di perairan tersebut masih baik atau lestari dan dapat menambah upaya penangkapan sebesar 10\% (Hordyk et al. 2014). Nilai SPR pada bulan Januari-Februari 2017 (musim barat) yaitu sebesar 18\% atau 0,18 yang artinya bahwa pada musim barat telah terjadi over exploited dikarenakan tekanan penangkapan yang tinggi dan ikan yang tertangkap banyak yang berusia masih juvenil atau berada di bawah nilai $\mathrm{Lm}$ (Pratiwi 2017).

Pembagian musim di Indonesia menurut Realino et al. (2006) dibagi menjadi empat yaitu musim peralihan I (Maret, April, Mei), musim timur (Juni, Juli, Agustus), musim peralihan II (September, Oktober, November) dan musim barat (Desember, Januari, Februari). Hasil wawancara dengan nelayan, musim penangkapan ikan ekor kuning terjadi sepanjang tahun. Menurut Yuliana et al. (2016) ikan ekor kuning mempunyai indeks musim yang merata sepanjang tahun, tidak pernah mengalami musim paceklik maupun musim penangkapan.

Musim dan cuaca menjadi faktor penentuan daerah penangkapan ikan dan ukuran hasil tangkapan. Kondisi perairan pada musim peralihan I arus dan gelombang perairan tidak besar, sehingga nelayan dapat menangkap ikan ke tengah laut. Ukuran ikan yang tertangkap pada musim peralihan banyak ikan yang layak tangkap karena ikan ekor kuning banyak berukuran besar dan berusia dewasa. Namun, hasil tangkapan pada musim barat banyak ikan ekor kuning yang tidak layak tangkap (Pratiwi 2017). Kondisi musim barat cuacanya tidak mendukung para nelayan untuk melaut ke tengah laut dikarenakan angin dan arus perairan cukup tinggi. Angin dan arus perairan yang cukup tinggi dapat mengancam keselamatan nelayan ketika melaut.

Nelayan yang menggantungkan hidupnya hanya melalui menangkap ikan di laut saja akan tetap menangkap ikan di laut. Nelayan memilih menangkap ikan di sekitar pulau-pulau terdekat dan umumnya di sekitar terumbu karang ketika musim barat. Ikan ekor kuning yang tertangkap di terumbu karang masih berukuran kecil dan belum layak tangkap. Terumbu karang bagi ikan itu sendiri sebagai habitat vitalnya yaitu tempat pemijahan (spawning ground), pengasuhan (nursery ground) dan mencari makan (feeding ground) (Utomo et al. 2013).

Perbedaan musim penangkapan menjadi pengaruh yang sangat besar dalam hasil tangkapan ikan di suatu perairan, karena setiap ikan memiliki pola pertumbuhan yang berbeda-beda di setiap musimnya. Pada musim barat nelayan melakukan penangkapan di sekitar pulau-pulau terdekat dan menangkap di sekitar terumbu karang. Pihak pengelola perikanan perlu mengatur terkait jumlah kuota penangkapan pada musim-musim tertentu, karena apabila pada musim barat terjadi penangkapan yang tinggi maka ikan yang tertangkap banyak yang masih juvenil dan belum layak tangkap. Apabila ini terus berlanjut maka tidak adanya kesempatan ikan ekor kuning melakukan pembesaran dan rekrutmen kembali.

Harvest strategies adalah strategi untuk membuat keputusan pengelolaan perikanan seperti pengaturan kuota. Pengaturan kuota dapat dilakukan dengan cara program pemantauan, metode penilaian stok atau sumberdaya, indikator perikanan lainnya dan peraturan pengendalian panen atau penangkapan (Hermann 2015). Harvest strategies telah diterapkan di Australia. Kebijakan harvest strategies ini ditujukan untuk pembatasan kuota penangkapan untuk menjaga ketersediaan stok sumberdaya ikan. Pada bulan November 2005 hingga November 2006 terjadi pengurangan jumlah armada penangkapan ikan yang disebabkan karena penyesuaian dari implementasi kebijakan tersebut sehingga kondisi stok sumberdaya ikan dapat dikontrol dan dikelola dengan baik (Smith et al. 2013).

Karimunjawa merupakan salah satu Taman Nasional yang ada di Indonesia, oleh karena itu perlu adanya pengelolaan yang efektif dan efisien untuk keberlanjutan dibidang perikanan tangkap. Pengelolaan dalam bentuk RBFM (Rights-Based Fisheries Management) dapat dilakukan berdasarkan kesepakatan bersama antara institusi pemerintah, lembaga swadaya masyarakat dan penduduk lokal 
terkait pengaturan wilayah atau daerah yang dapat dimanfaatkan, ukuran ikan dan jenis ikan yang diperbolehkan untuk ditangkap dan alat tangkap yang digunakan.

\section{KESIMPULAN DAN SARAN}

Status stok sumberdaya ikan ekor kuning pada bulan Maret-April 2018 (musim peralihan I) dalam kategori under exploited dengan nilai kematian akibat penangkapan terhadap kematian alami ( $F / M$ ) 1,44, Spawning Potential Ratio 0,50 dan rata-rata ukuran ikan yang tertangkap lebih besar dari ukuran panjang pertama kali ikan matang gonad ( $S L 50>L m$ ). Pada musim peralihan (Maret-April 2018) ikan yang tertangkap sudah layak tangkap, namun penangkapan ikan tetap perlu diperhatikan selektivitas alat tangkapnya dan lokasi pengoperasiannya agar tidak menangkap ikan yang masih berukuran kecil atau berusia muda.

\section{DAFTAR PUSTAKA}

Brooks EN, Powers JE, Cortes E. 2010. Analytical reference points for age-structured models: application to data-poor fisheries. ICES Journal Marine Science 67: 165-175.

Effendie MI. 1997. Biologi Perikanan. Yogyakarta (ID): Yayasan Pustaka Nusatama.

Froese RC dan Binohlan C. 2000. Empirical relationship to estimate asymptotic length at first maturity and length at maximum yield per recruit in fishes with a simple method to evaluate length frequency data. Journal of Fish Biology. 56(4):758 - 773

Habibun. 2011. Aspek pertumbuhan dan reproduksi ikan ekor kuning (Caesio cuning) yang didaratkan di Pangkalan Pendaratan Ikan Pulau Pramuka, Kepulauan Seribu, Jakarta. [skripsi]. Bogor (ID): Institut Pertanian Bogor.

Hermann R. 2015. Harvest strategies: the next phase of fisheries management. [internet] [Diakses pada tanggal 10 Desember 2017]. Tersedia pada: http://www.pewtrust.org.

Hordyk A, Ono K, Valencia S, Loneragan N, Prince J. 2014. A novel length-based empirical estimation method of spawning potential ratio (SPR) and tests of its performance, for small scale, data-poor fisheries. ICES Journal Marine Science. 72(1): 217-231.

Irnawati R, Simbolon D, Wiryawan B, Murdiyanto B, Nurani TW. 2011. Analisis Komoditas Unggulan Perikanan Tangkap di Taman Nasional Karimunjawa. Jurnal Saintek Perikanan. 7(1): 1-9

Pelabuhan Perikanan Pantai Karimunjawa. 2018. Laporan Tahunan 2017. Semarang, Jawa Tengah (ID): Pekabuhan Perikanan Pantai Karimunjawa.

Pratiwi SU. 2017. Rasio Potensi Pemijahan Ikan Ekor Kuning (Caesio cuning) Sebagai Input Pengelolaan Perikanan Tangkap di Perairan Karimunjawa. [skripsi]. Bogor (ID): Institut Pertanian Bogor.

Prince J, Hordyk A, Sarah R, Neil L, Keith S. 2014. Revisiting the concept of beverton - holt life-history invariants with the aim of informing data-poor fisheries assessment. ICES Journal Marine Science. 72(1): 194-203.

Realino B, Teja AW, Dedy AZ, Asmi MN.2006. Pola spasial dan temporal kesuburan perairan permukaan laut di Indonesia. Balai Riset dan Observasi Kelautan.

Romimohtarto K dan Juwana S.2001. Biologi Laut; Ilmu Tentang Biota Laut. Jakarta(ID): Djambatan. 
Simbolon D, Irnawati R, Wiryawan B, Murdiyanto B dan Nurani TW.2016. Zona penangkapan ikan di taman nasional karimunjawa. Jurnal Ilmu dan Teknologi Kelautan Tropis. 8(1): 129-143.

Smith A D M, Smith D C, Haddon M, Knuckey I A, Sainsbury K J dan Sloan S R. 2013. Implementing harvest strategies in Australia: 5 years on. ICES Journal Marine Science. 71(2): 195-203.

Sugiyono. 2016. Metode Penelitian Kuantitatif Kualitatif dan RnD. Bandung(ID): CV ALFABETA.

Sukandarrumidi. 2012. Metode Penelitian. Yogyakarta(ID): Gadjah Mada University Press

Triyono H, Goenawati I, Siswanti NS. 2011. The biological and fishing aspect of Caesio cuning which is landed in the Karimunjawa fishing port, Jepara Regency, Central Java Province. Sekolah Tinggi Perikanan, Jakarta. [Indonesian].

Utomo S, Anin C, Supriharyono. 2013. Keanekaragaman jenis ikan karang di daerah rataan dan tubir pada ekosistem terumbu karang di Legon Boyo, Taman Nasional Karimunjawa. Diponegoro Jurnal of Maquares. 2(4): 81-90.

Yuliana E, Mennofatria B, Achmad F, M Muklis K, Muttaqin E.2016. Status stok ikan karang target di kawasan konservasi Taman Nasional Karimunjawa/ Jurnal Perikanan Indonesia. 22(1): 9-16.

Yuliana E, Mennofatria B, Achmad F, M Muklis K. 2016. Biodiversitas ikan karang di kawasan konservasi taman nasional karimunjawa. Jurnal Ilmu dan Teknologi Kelautan Tropis. 9(1): 2943. 